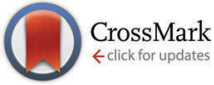

Cite this: Chem. Commun., 2016, 52,4898

Received 18th February 2016, Accepted 4th March 2016

DOI: $10.1039 / c 6 c c 01493 c$

www.rsc.org/chemcomm

\section{New outcomes of Lewis base addition to diboranes(4): electronic effects override strong steric disincentives $\dagger$}

\author{
Nicole Arnold, ${ }^{a}$ Holger Braunschweig, ${ }^{* a}$ Alexander Damme, ${ }^{a}$ Rian D. Dewhurst, ${ }^{a}$ \\ Leanne Pentecost, ${ }^{b}$ Krzysztof Radacki, ${ }^{a}$ Sascha Stellwag-Konertz, ${ }^{a}$ Torsten Thiess, ${ }^{a}$ \\ Alexandra Trumpp ${ }^{a}$ and Alfredo Vargas ${ }^{b}$
}

Two surprising new outcomes of the reaction of Lewis bases with dihalodiboranes(4) are presented, including $s p^{2}-s^{3}$ diboranes in which the Lewis base unit is bound to a highly sterically congested boron atom, and a rearranged double base adduct. The results provide a fuller understanding of the reactivity of diboranes, a poorlyunderstood class of molecule of critical importance to synthetic organic chemistry.

After centuries of research, saturated acyclic chains of carbon atoms - alkanes - offer few surprises in contemporary organic chemistry. Likewise, other compounds with first-row main group homoatomic single bonds (N-N, O-O and F-F) are relatively well understood, albeit significantly more limited in number. In marked contrast, the remaining first-row main group element boron - is distinctly reluctant to form such electron-precise, saturated homoatomic bonds. The chemistry of the simplest boron-based alkane analogues - diboranes $(4)\left(R_{2} B B R_{2}\right)$ - is still in its infancy. Even setting aside the research that is providing a pipeline of borylated precursors for Suzuki-Miyaura crosscoupling reactions for the pharma, agrochemical and fine chemical industries, ${ }^{1}$ the field of diborane chemistry is witnessing strong growth spurred on by the frequent discovery of new capabilities of these compounds, such as substituent rearrangements, bridging interactions, bond activations and metal-free borylation reactions. A large amount of recent work and a number of reviews on the topics of B-B bond construction and the chemistry of $\mathrm{sp}^{2}-\mathrm{sp}^{3}$ diboranes highlight both the growing interest in this chemistry and its enormous potential. ${ }^{2}$

One of the most unpredictable classes of diboranes(4) are the dihalodiboranes(4), the substituents of which can rearrange both spontaneously and in the presence of bases. ${ }^{2,3}$ This process,

\footnotetext{
${ }^{a}$ Institut für Anorganische Chemie, Julius-Maximilians-Universität Würzburg, Am Hubland, 97074 Würzburg, Germany. E-mail: h.braunschweig@uni-wuerzburg.de ${ }^{b}$ Department of Chemistry, School of Life Sciences, University of Sussex,

Brighton BN1 9QJ, Sussex, UK

$\dagger$ Electronic supplementary information (ESI) available: Synthetic and crystallographic details. CCDC 1452951-1452954. For ESI and crystallographic data in CIF or other electronic format see DOI: 10.1039/c6cc01493c
}

involving the movement of substituents between $\mathrm{sp}^{2}$ atoms with empty p orbitals, is reminiscent of the Wagner-Meerwein rearrangement of alkyl groups in aliphatic carbocations. ${ }^{4}$ The first report of this behaviour came from the group of Berndt in 1991, wherein substitution of chlorides of symmetrical 1,2-diaryl1,2-dichlorodiboranes(4) by fluoride proceeded with concomitant rearrangement to the unsymmetrical 1,1-diaryl-2,2-difluorodiboranes(4) (e.g. 1, Fig. 1). ${ }^{5}$ The preference of the bulky aryl (mesityl, duryl) groups to both bind to the same boron atom was particularly surprising. More recently, we reported a number of similar rearrangements of 1,2-diaryl-1,2-dihalodiboranes(4) in the presence of Lewis bases, as well as isolation of basestabilised diboranes(4) with halides bridging the boron atoms, assumed to be arrested rearrangement products. ${ }^{3}$ Reactions of bases with 1,2-dialkyl-1,2-dihalodiboranes(4) and 1,2-diamino1,2-dihalodiboranes(4) uncovered further possibilities, such as simple (non-rearranged) adducts, $\mathrm{C}-\mathrm{H}$ activation products and halide abstraction to form borylborenium cations. Together, these five outcomes represented a diverse range of structural outcomes from a seemingly simple reaction.

Herein, we report the surprising synthesis of adducts with Lewis bases bound instead to the sterically congested diaryl boron atom, as well as the formation of a (unsymmetrical-to-symmetrical)
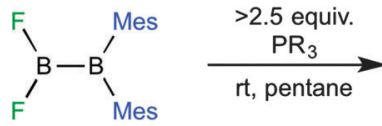

1
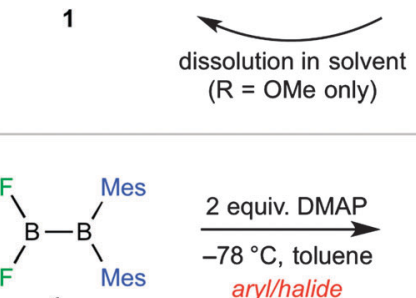

1

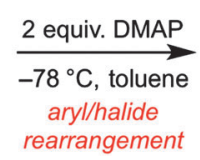

Fig. 1 Synthesis of diborane adducts 2 and 3 . DMAP $=N, N$-dimethylpyridine4-amine. 
rearranged double base adduct. The preferences for base-ligation at the different boron atoms of 1,1-diaryl-2,2-dihalodiboranes are evaluated computationally in order to rationalise the observed results.

When the unsymmetrical diborane(4) 1,1-dimesityl-2,2-difluorodiborane(4) (1, Fig. 1) ${ }^{5}$ was treated with 5.8 equiv. of $\mathrm{PMe}_{3},{ }^{31} \mathrm{P}$ and ${ }^{11} \mathrm{~B}$ NMR spectra of the reaction mixture indicated conversion to a single boron-containing product, with both $\mathrm{sp}^{2}$ and $\mathrm{sp}^{3}$ boron centres $\left(\delta_{\mathrm{B}} 35.9,-12.7 ; \delta_{\mathrm{P}}-16.4\right)$. Due to its high solubility in pentane, only a low yield of the isolated compound could be obtained (2a, Fig. 1). The downfield ${ }^{11} \mathrm{~B}$ NMR resonance of $2 \mathrm{a}$ at $\delta_{\mathrm{B}} 35.9$ is only moderately shifted from the corresponding resonance of precursor $1\left(\delta_{\mathrm{B}} \sim 29\right)$, suggesting that no rearrangement had taken place, while the upfield signal at $\delta_{\mathrm{B}}$ -12.7 is shifted markedly from its original position $\left(\delta_{\mathrm{B}} \sim 82\right)$. That the downfield resonance of 1 shifts most upon base addition suggested that the base binds not to the $\mathrm{BF}_{2}$ unit but to the highly congested $\mathrm{BMes}_{2}$ unit. A similar reaction of $\mathbf{1}$ with 2.5 equiv. trimethylphosphite resulted in no observable conversion by ${ }^{11} \mathrm{~B}$ and ${ }^{31} \mathrm{P}$ NMR spectroscopy. However, a low yield of colourless crystals was isolated from the reaction mixture that provided elemental analysis data consistent with a Lewis base mono-adduct and allowed determination of a solid-state structure (vide infra). Redissolving these crystals resulted in complete reversion to precursors 1 and $\mathrm{P}(\mathrm{OMe})_{3}$ in a 1:1 molar ratio, preventing the collection of NMR spectra.

The crystallographically-determined structures of $\mathbf{2 a}$ and 2b confirm the base addition at the diaryl-substituted boron centres (Fig. 2). Both structures suffer from disorder related to different orientations of the planar $\mathrm{BF}_{2}$ group, leading to unreliable $\mathrm{B}-\mathrm{F}$ distances. The $\mathrm{B}-\mathrm{B}$ distances of the compounds are identical within experimental uncertainty (2a: 1.704(3) A; 2b: $1.711(4) \AA$ ), and, interestingly, are statistically identical to the $\mathrm{B}-\mathrm{B}$ bond of the analogous, base-free diborane(4) $\mathrm{B}_{2} \mathrm{~F}_{2}$ Dur (Dur = 2,3,5,6-tetramethylphenyl; B-B 1.697(3) Å; see ESI, $\dagger$ for solid-state structure). The P-B distance of $2 \mathbf{b}(1.959(2) \AA)$ is ca. $5 \%$ shorter than that of $2 \mathrm{a}(2.050(2) \AA)$. Similarly small P-B distances in phosphite-boranes have been observed in the literature; for instance, the $\mathrm{P}-\mathrm{B}$ bond in $(\mathrm{MeO})_{3} \mathrm{P} \rightarrow \mathrm{B}\left(\mathrm{C}_{6} \mathrm{~F}_{5}\right)_{3}$ $(2.021(1) \AA)^{6}$ is shorter than that of $\mathrm{Me}_{3} \mathrm{P} \rightarrow \mathrm{B}\left(\mathrm{C}_{6} \mathrm{~F}_{5}\right)_{3}(2.061(4) \AA),{ }^{7}$ but only by $c a$. $2 \%$. The $\mathrm{sp}^{3}$ boron atoms of $\mathbf{2 a}$ and $\mathbf{2 b}$ are strongly distorted from tetrahedral, with the sums of their B-B/C distances (2a $\left.\sum(\angle \mathrm{B}-\mathrm{X}): 334.01^{\circ} ; 2 \mathrm{~b} \sum(\angle \mathrm{B}-\mathrm{X}): 331.98^{\circ}\right)$ being significantly higher than that expected for a perfect tetrahedron $\left(328.5^{\circ}\right)$. These angular sums indicate splayed $\mathrm{BX}_{3}$ units, while further distortion is indicated by the presence of one small and one large B-B-C angle in each structure (2a: B-B-C 99.2(1) and $120.8(1)^{\circ}$; 2b: $\mathrm{B}-\mathrm{B}-\mathrm{C}$ 95.5(2) and $\left.124.0(2)^{\circ}\right)$. This distortion is more pronounced in $\mathbf{2 b}$, perhaps a consequence of its significantly shorter P-B bond, and is possibly a contributor to the observed instability of this compound. These parameters suggest a large amount of strain at the $\mathrm{sp}^{3}$ boron atom of both compounds, and that the connectivity observed is strongly disfavoured from a steric viewpoint.

The apparent distortion in adducts 2 leads us to the conclusion that the binding site of the base is electronically controlled.

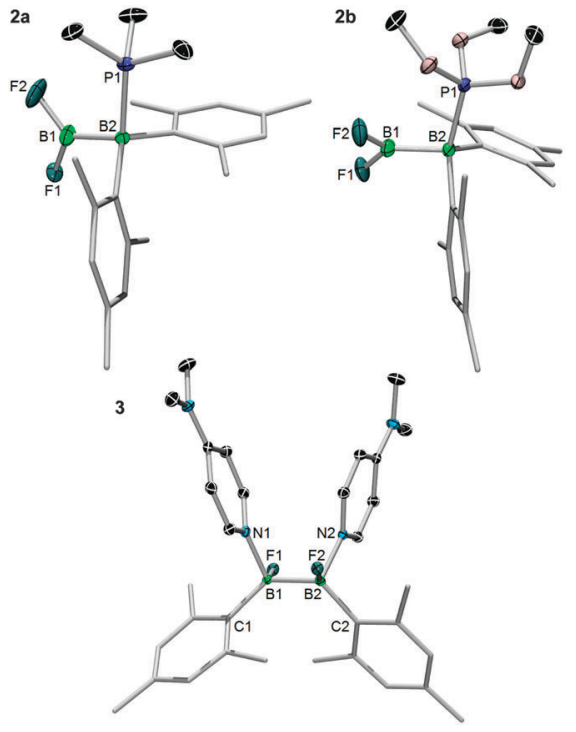

Fig. 2 Crystallographically-derived structures of $\mathbf{2 a}, \mathbf{2} \mathbf{b}$, and $\mathbf{3}$, with thermal ellipsoids shown at the $50 \%$ probability level. Hydrogen atoms, ellipsoids of the mesityl groups, and solvent molecules (one molecule of $\mathrm{CH}_{2} \mathrm{Cl}_{2}$ for 3 ) are removed for clarity. Selected bond lengths ( $(\AA)$ and angles $\left({ }^{\circ}\right)$ for 2a: B1-B2 1.704(3), B1-F1 1.359(5), B1-F2 1.24(3), P1-B2 2.050(2); $B 1-B 2-P 1$ 103.9(1). For 2b: B1-B2 1.711(4), B1-F1 1.336(2), B1-F2 1.338(2), $\mathrm{P} 1-\mathrm{B} 2$ 1.959(2); B1-B2-P1 102.3(2). For 3: B1-B2 1.794(4), B1-F1 1.444(3), $\mathrm{B} 1-\mathrm{N} 1$ 1.649(3), B2-F2 1.434(3), B2-N2 1.652(3); B1-B2-N2 101.8(2), B1$B 2-F 2$ 110.2(2), B2-B1-N1 103.2(2), B2-B1-F1 109.1(2), torsion N1-B1B2-N2 64.22, torsion F1-B1-B2-F2 152.45, torsion C1-B1-B2-C2 63.52.

While there is certainly no universal measure of Lewis acidity, $\mathrm{BF}_{3}$ is generally accepted to be a slightly stronger Lewis acid than $\mathrm{BPh}_{3},{ }^{8}$ the electronics of which should not be vastly different from $\mathrm{BMes}_{3}$. It should be noted that the $-\mathrm{BMes}_{2}$ unit is used extensively in the synthesis of $\pi$-conjugated molecules and molecular materials, due to its combination of high $\pi$ acidity and steric shielding that imparts kinetic protection from attack by nucleophiles, ${ }^{9}$ thus the observed base addition to this site is a surprising outcome.

In an attempt to prepare further examples of $\mathrm{sp}^{2}-\mathrm{sp}^{3}$ diboranes from 1, the diborane(4) was treated with 0.9 molar equivalents of $N, N$-dimethylpyridine-4-amine (DMAP). The reaction produces a number of different products, of which only the bis(base) adduct 3 could be isolated in low yield and fully characterised (Fig. 1). The yield of 3 could be increased to $27 \%$ by repeating the reaction with 2.0 equivalents of DMAP. The symmetrical nature of 3 is evident from its single ${ }^{11} \mathrm{~B}\left(\delta_{\mathrm{B}} 6.8\right)$ and ${ }^{19} \mathrm{~F}\left(\delta_{\mathrm{F}}-139.8\right) \mathrm{NMR}$ resonances. The solid-state structure of 3 confirms the double coordination of DMAP units to the diborane(4) unit (Fig. 2). Looking down the B-B bond of 3 , the six substituents are staggered, with the $\mathrm{F}$ groups approximately anti (torsion ca. $152^{\circ}$ ), the Mes groups syn (torsion ca. 63 ${ }^{\circ}$ ), and the DMAP bases syn (torsion $\mathrm{ca} .64^{\circ}$ ), respectively. The B-N distances of 3 (1.649(3), $1.652(3) \AA)$ are very similar to those of bis(4-methylpyridine) adducts of diboranes(4) (ca. 1.64-1.66 ̊). ${ }^{10}$ However, the B-B distance $(1.794(4) \AA)$ is significantly longer than those of the published compounds ( $c a$. 1.71). It should be noted that doubly base-stabilised diboranes(4) are well known in the literature, 


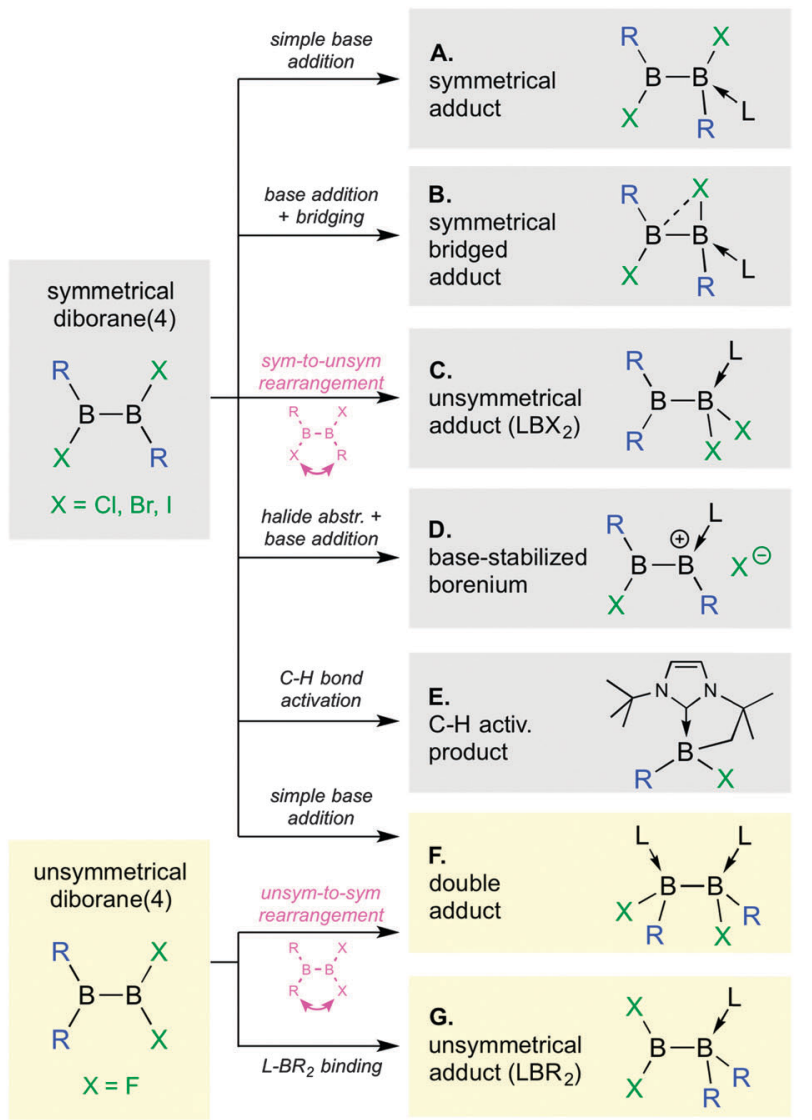

Fig. 3 Overall chart of the structurally diverse products of base addition to dihalodiboranes(4). Work presented herein is shaded in yellow, other results have been published previously. ${ }^{3}$

including one example of a doubly base-stabilised diorganyldihalodiborane(4).$^{11}$ However, complex 3 is distinguished from these examples by the fact that its synthesis involves the unusual unsymmetrical-to-symmetrical rearrangement.

Fig. 3 shows a chart of the outcomes of the reactions of dihalodiboranes with Lewis bases, with the products from this work shaded in yellow. The table highlights the remarkable diversity of the reaction when the relatively small differences between the precursors are considered. Changing the halide to fluoride in $\mathbf{1}$ clearly suppress the Lewis acidity of the attached boron atom such that the base chooses to bind at the diarylboryl site in compounds $\mathbf{2} \mathbf{a}, \mathbf{b}$ or induces rearrangement in order to provide enough acidity to favour formation of dative $\mathrm{N} \rightarrow \mathrm{B}$ bonds in 3.

To better understand the isomeric selectivity of the diboranes, calculations were undertaken within the Kohn-Sham DensityFunctional Theory (DFT). Fig. 4 shows the calculated relative total electronic energies of the different minimized isomers of $\left(\mathrm{B}_{2} \mathrm{X}_{2} \mathrm{Mes}_{2}\right)\left(\mathrm{PMe}_{3}\right)(\mathrm{X}=\mathrm{F}, \mathrm{Cl}, \mathrm{Br})$ adducts of type $\mathbf{C}$ and $\mathbf{G}$ as depicted in Fig. 3. The third minimised isomer for each halide case was found to be midway between the non-bridged type $\mathbf{A}$ (B-B-X angle $>90^{\circ}$ ) and halide-bridged type $\mathrm{B}$ (with a $\mathrm{B}-\mathrm{B}-\mathrm{X}$ angle $<90^{\circ}$ ). It can be immediately noticed that when $\mathrm{X}=\mathrm{F}$, type $\mathbf{G}$ is more stable than type $\mathbf{C}$ by $c a .13 \mathrm{~kJ} \mathrm{~mol}^{-1}$,

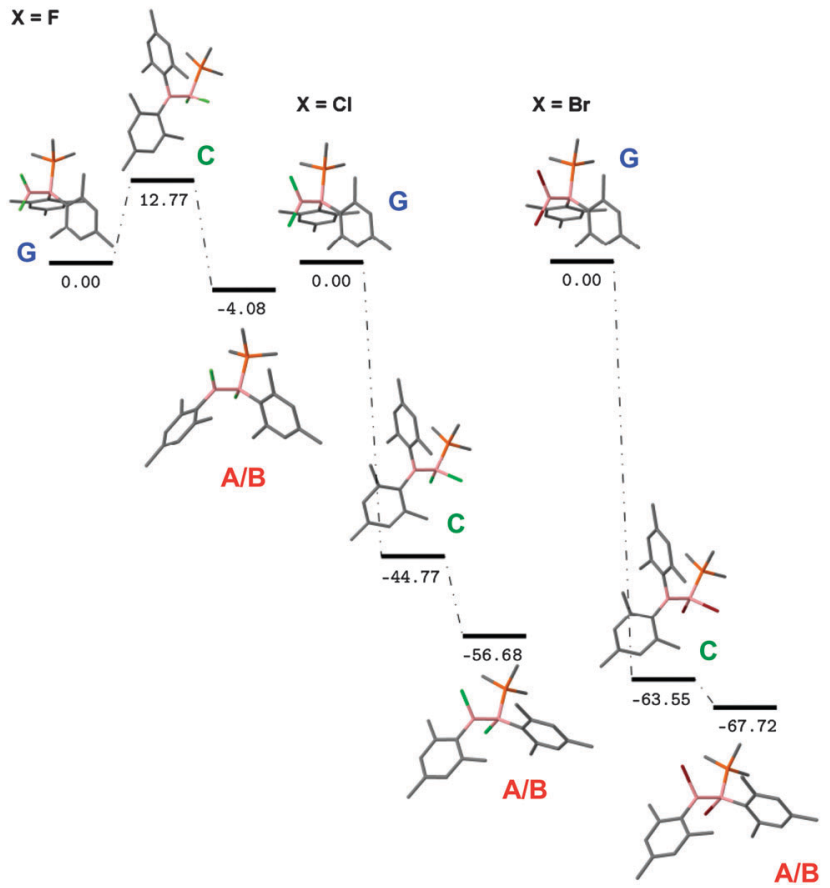

Fig. 4 Calculated relative total electronic energies $\left(\mathrm{kJ} \mathrm{mol}^{-1}\right)$ of molecules of types $\mathbf{A} / \mathbf{B}, \mathbf{C}$ and $\mathbf{G}$ with $\mathrm{R}=\mathrm{Mes}, \mathrm{X}=\mathrm{F}, \mathrm{Cl}, \mathrm{Br}$ and $\mathrm{L}=\mathrm{PMe}_{3}$.

although the hybrid isomer of type $\mathbf{A} / \mathbf{B}$ is slightly more stable than $\mathbf{G}$ (by $c a .4 \mathrm{~kJ} \mathrm{~mol}^{-1}$ ). When $\mathrm{X}=\mathrm{Cl}$ or $\mathrm{Br}$, then type $\mathbf{C}$ is much more stable than $\mathbf{G}$ (by 45 or $64 \mathrm{~kJ} \mathrm{~mol}^{-1}$, respectively), while the hybrid type $\mathbf{A} / \mathbf{B}$ is more stable than $\mathbf{C}$ by a further 12 or $4 \mathrm{~kJ} \mathrm{~mol}^{-1}$. These results corroborate the earlier-reported preference for $\mathrm{X}=\mathrm{Cl}, \mathrm{Br}$, where the bridged adducts $\mathbf{B}$ are observed in the solid state. However, that the hybrid $\mathbf{A} / \mathbf{B}$ structure is lower in energy in the $\mathrm{X}=\mathrm{F}$ case suggests that the experimental absence of such a structure may be a kinetic obstacle, as to form such a compound one halide and one mesityl group of the unsymmetrical precursor 1 must switch places.

Computational techniques also provided plausible rationales for the unusual combination of high selectivity and highly variable structural outcomes observed in these diborane(4) Lewis adducts. Boron possesses unique abilities in terms of the 'conveyance' of charge flux, ${ }^{12}$ which are responsible for many of the outstanding properties of boron-containing compounds. Results from calculations suggest that the total electronic energy of diborane adducts is a function of the 'charge-separation' state of the B-B core. Indeed, Tables S1-S4 (ESI $\dagger$ ) show that the $\mathrm{sp}^{2}$ boron atoms carry a positive partial charge, in contrast to the base-bound boron which in general carries a negative partial charge. It is clear that the boron partial charge depends on the nature of the neighbouring connected atoms or functional groups. The two fluorides of the $\mathrm{BF}_{2}$ unit strongly withdraw electron density from the boron, while in the $\mathrm{BMes}_{2}$ unit, the boron should support being slightly cationic as one Mes group can electronically stabilise it through resonance and induction, as evidenced by extensive $\sigma$ and $\pi$ interactions between B and the $\mathrm{C} 1$ atom of the one coplanar mesityl group. But because the boron atom interacting with the base is connected to another 
boron atom, the withdrawing effect presumably extends to the $\beta$ boron atom. Hence the nature of the halide and the $\mathrm{R}$ group dictates at which acidic site the base binds in such a way as to have maximum $\mathrm{BB}$ charge difference, ${ }^{2 d, 13}$ i.e., in a manner in which the acid-base interaction is strongest. This can be seen for instance by considering the B-L bond lengths. This reasoning is summed up in the following simple equation: $E_{\text {tot }} \propto \kappa$, where $\kappa=q_{\mathrm{B}(\mathrm{x})} \times q_{\mathrm{B}(\mathrm{R})} \times q(\mathrm{~b}) \times d(\mathrm{BB})$. In other words, the energy (and hence stability) depends on: the partial charge of both borons (reflecting the ease of charge movement conferred by the boron centres), the partial charge of the base (which takes into account its donating power) and lastly the boron-boron bond length (which takes into account any $\pi(\mathrm{BB})$ donation, negative hyperconjugation between the $\mathrm{BB}$ substituents, etc.). Hybridisation does not seem to be very influential, as could be expected in the case of boron. The approach was tested and applied on model systems where $\mathrm{R}=\mathrm{Me}$, Ph. Setting $\mathrm{R}=\mathrm{Me}$, the $\kappa$ values closely follow the trends in total energy; moreover, when $\mathrm{X}=\mathrm{F}$ in the type $\mathbf{C}$ conformation, the base migrates to the diaryl side, indicating the inability of the methyl groups to stabilise a cationic $\mathrm{B}^{+}$centre, in line with the scheme described above. In the case of $\mathrm{R}=\mathrm{Ph}$, the values are intermediate between those obtained when $\mathrm{R}=$ Mes and Me (data not shown). The validity of the model systems in terms of energetics and structure can be extended to the case where DMAP is used as base. When using the $\mathrm{X}=\mathrm{F}$, Cl models, the type $\mathbf{C}$ isomer is more stable than type $\mathbf{G}$, as predicted using the aforementioned parameters.

In conclusion, the seemingly counterintuitive experimental observation of a Lewis base attacking the more stericallyhindered boron atom of an unsymmetrical diborane(4) can be ascribed to electronic effects. The results can be summarised as follows: (a) the system seeks to form the Lewis adduct where the donor-acceptor interaction is maximised (either side of the diborane), (b) this results in a 'charge-separated'-like state within the BB unit, the cationic side being stabilised by $\sigma$ and/or $\pi$ electron donation, or by having strongly electronegative elements able to extend their $\sigma$-withdrawing effects to the boron in the $\beta$ position.

These reactions further expand the remarkable number of outcomes of reactions between dihalodiboranes(4) and Lewis bases, and bring us closer to a more complete understanding of the chemistry of diboranes(4) - a class of molecule that is rapidly becoming a critical intermediate in synthetic organic chemistry.

Financial support for this work from the University of Sussex (A. V.) and the EPSRC (A. V.) is gratefully acknowledged.

\section{Notes and references}

1 (a) Cross-coupling reactions of organoboranes: an easy way for C-C bonding (Nobel lecture), A. Suzuki, 2010, http://www.nobelprize.org/; (b) T. B. Marder and N. C. Norman, Top. Catal., 1998, 5, 63-73; (c) Boronic Acids: Preparation and Applications in Organic Synthesis, Medicine and Materials, ed. D. G. Hall, Wiley-VCH, Weinheim, Germany, 2006; (d) I. A. I. Mkhalid, J. H. Barnard, T. B. Marder,
J. M. Murphy and J. F. Hartwig, Chem. Rev., 2010, 110, 890-931; (e) J. F. Hartwig, Acc. Chem. Res., 2012, 45, 864-873.

2 (a) H. Braunschweig and R. D. Dewhurst, Angew. Chem., Int. Ed., 2013, 52, 3574-3583; (b) H. Braunschweig, R. D. Dewhurst and S. Mozo, ChemCatChem, 2015, 7, 1630-1638; (c) H. Gulyás, A. Bonet, C. Pubill-Ulldemolins, C. Solé, J. Cid and E. Fernández, Pure Appl. Chem., 2012, 84, 2219-2231; (d) J. Cid, H. Gulyás, J. J. Carbó and E. Fernández, Chem. Soc. Rev., 2012, 41, 3558-3570; (e) R. D. Dewhurst, E. C. Neeve, H. Braunschweig and T. B. Marder, Chem. Commun., 2015, 51, 9594-9607; $(f)$ M. Gao, S. B. Thorpe and W. L. Santos, Org. Lett., 2009, 11, 3478-3481; $(g)$ A. Bonet, H. Gulyás and E. Fernández, Angew. Chem., Int. Ed., 2010, 49, 5130-5134; (h) M. Gao, S. B. Thorpe, C. Kleeberg, C. Slebodnik, T. B. Marder and W. L. Santos, J. Org. Chem., 2011, 76, 3997-4007; (i) S. B. Thorpe, X. Guo and W. L. Santos, Chem. Commun., 2011, 47, 424-426; (j) C. Kleeberg, A. G. Crawford, A. S. Batsanov, P. Hodgkinson, D. C. Apperley, M. S. Cheung, Z. Lin and T. B. Marder, J. Org. Chem., 2012, 77, 785-789; ( $k$ ) C. Borner and C. Kleeberg, Eur. J. Inorg. Chem., 2014, 2486-2489; (l) S. Pietsch, E. C. Neeve, D. C. Apperley, R. Bertermann, F. Mo, D. Qiu, M. S. Cheung, L. Dang, J. Wang, U. Radius, Z. Lin, C. Kleeberg and T. B. Marder, Chem. - Eur. J., 2015, 21, 7082-7098.

3 (a) P. Bissinger, H. Braunschweig, A. Damme, R. D. Dewhurst, T. Kupfer, K. Radacki and K. Wagner, J. Am. Chem. Soc., 2011, 133, 19044-19047; (b) H. Braunschweig, A. Damme, J. O. C. JimenezHalla, T. Kupfer and K. Radacki, Angew. Chem., Int. Ed., 2012, 51, 6267-6271; (c) H. Braunschweig, A. Damme and T. Kupfer, Chem. Commun., 2013, 49, 2774-2776; (d) H. Braunschweig, A. Damme, R. D. Dewhurst, T. Kramer, T. Kupfer, K. Radacki, E. Siedler, A. Trumpp, K. Wagner and C. Werner, J. Am. Chem. Soc., 2013, 135, 8702-8707.

4 (a) J. Clayden, N. Greeves, S. Warren and P. Wothers, Organic Chemistry, Oxford University Press, Oxford, 2001; (b) G. Wagner and W. Brickner, Ber. Dtsch. Chem. Ges., 1899, 32, 2302-2325; (c) H. Meerwein, Liebigs Ann. Chem., 1914, 405, 129-175; (d) G. A. Olah, Acc. Chem. Res., 1976, 9, 41-52.

5 A. Höfner, B. Ziegler, R. Hunold, P. Willershausen, W. Massa and A. Berndt, Angew. Chem., Int. Ed., 1991, 30, 594-596.

6 R. C. Neu, E. Y. Ouyang, S. J. Geier, X. Zhao, A. Ramos and D. W. Stephan, Dalton Trans., 2010, 39, 4285-4294.

7 P. A. Chase, M. Parvez and W. E. Piers, Acta Crystallogr., 2006, E62, o5181-05183.

8 (a) A. F. Holleman, E. Wiberg and N. Wiberg, Lehrbuch der Anorganischen Chemie, Walter de Gruyter, Berlin, New York, 2007, p. 1099; (b) M. Méndez and A. Cedillo, Comput. Theor. Chem., 2013, 1011, 44-56; (c) I. B. Sivaev and V. I. Bregadze, Coord. Chem. Rev., 2014, 270-271, 75-88.

9 (a) Z. Yuan, J. C. Collings, N. J. Taylor, T. B. Marder, C. Jardin and J.-F. Halet, J. Solid State Chem., 2000, 154, 5-12; (b) C. D. Entwistle and T. B. Marder, Angew. Chem., Int. Ed., 2002, 41, 2927-2931; (c) C. D. Entwistle and T. B. Marder, Chem. Mater., 2004, 16, 4574-4585; (d) Z. M. Hudson and S. Wang, Acc. Chem. Res., 2009, 42, 1584-1596; (e) S. Yamaguchi and A. Wakamiya, Pure Appl. Chem., 2006, 78, 1413-1424; $(f)$ F. Jäkle, Boron: Organoboranes, in Encyclopedia of Inorganic Chemistry, ed. R. B. King, Wiley, Chichester, U.K., 2nd edn, 2005.

10 (a) P. Nguyen, C. Dai, N. J. Taylor, W. P. Power, T. B. Marder, N. L. Pickett and N. C. Norman, Inorg. Chem., 1995, 34, 4290-4291; (b) W. Clegg, C. Dai, F. J. Lawlor, T. B. Marder, P. Nguyen, N. C. Norman, N. L. Pickett, W. P. Power and A. J. Scott, J. Chem. Soc., Dalton Trans., 1997, 839-846.

11 S. Pospiech, S. Brough, M. Bolte, H.-W. Lerner, H. F. Bettinger and M. Wagner, Chem. Commun., 2012, 48, 5886-5888.

12 (a) H. Braunschweig, A. Damme, R. D. Dewhurst, S. Ghosh, T. Kramer, B. Pfaffinger, K. Radacki and A. Vargas, J. Am. Chem. Soc., 2013, 135, 1903-1911; (b) H. Braunschweig, A. Damme, R. D. Dewhurst, T. Kramer, S. Östreicher, K. Radacki and A. Vargas, J. Am. Chem. Soc., 2013, 135, 2313-2320.

13 (a) A. Bonet, C. Pubill-Ulldemolins, C. Bo, H. Gulyás and E. Fernández, Angew. Chem., Int. Ed., 2011, 50, 7158-7161; (b) J. Cid, J. J. Carbó and E. Fernández, Chem. - Eur. J., 2012, 18, 12794-12802; (c) C. PubillUlldemolins, A. Bonet, C. Bo, H. Gulyás and E. Fernández, Chem. - Eur. J., 2012, 18, 1121-1126. 